\title{
Invited perspectives: A community perspective on natural hazards key challenges and the Sustainable Development Goals
}

\author{
Robert Šakić Trogrlić1,2, Amy Donovan ${ }^{3}$, Bruce D Malamud ${ }^{1}$ \\ ${ }^{1}$ Department of Geography, King's College London, London, WC2B 4BG, UK. \\ ${ }^{2}$ Systemic Risk and Resilience (SYRR) Group, Advancing Systems Analysis (ASA) Program, International Institute for \\ 6 Applied Systems Analysis (IIASA), Laxenburg, 2361, Austria. \\ ${ }^{3}$ Department of Geography, University of Cambridge, Cambridge, CB2 3EN, UK.
}

Correspondence to: bruce.malamud@kcl.ac.uk

\begin{abstract}
In this paper, we present the views of 350 members of the Natural Hazards and Earth System Sciences (NHESS) readership concerning (i) the key challenges in natural hazard sciences and (ii) the broad step changes necessary in the natural hazard research to help facilitate the implementation of the Sustainable Development Goals. We have analysed the data quantitatively and qualitatively, and note that while the most common knowledge gaps are felt to be around components of knowledge about risk drivers, the step changes that the community felt were necessary related more to issues of interdisciplinary working and stakeholder engagement.
\end{abstract}

\section{Introduction}

In their interaction with people, economies, and the built and natural environment, natural hazards result in small- and largescale disasters (Sidle et al., 2004; Luebken and Mauch, 2011). Understanding these hazards and devising creative ways to manage them and their impacts has always attracted interest from scientists, policy makers, and practitioners (Peek and Mileti, 2002). However, disaster risks are still mounting due to exacerbating climate change, increasing populations, accelerated urbanisation, and land-use change (Coronese et al., 2019; Glasser, 2020; WMO, 2021), amongst other factors and processes.

Therefore, it is of interest to assess gaps in understanding and management of natural hazards and the resulting risks. Given the importance of the United Nations Sustainable Development Goals (SDGs) (UNDRR, 2015) as the world's blueprint for sustainable futures, it is also noteworthy to explore the relationship between natural hazards sciences and their implementation (Gill and Smith, 2021). This includes considering the changes needed to overcome knowledge gaps to contribute to the implementation of the SDGs. This paper will focus on these natural hazard issues by providing some perspectives of the broader European Geosciences Union (EGU) natural hazard community. We do this through a questionnaire launched as part of the 20th anniversary of Natural Hazards and Earth System Sciences (NHESS). This paper summarises the responses of 350 natural hazard scientists, government workers and practitioners where we asked them via a questionnaire: (i) the top scientific 
challenges in our understanding of natural hazards, (ii) suggested step changes by the natural hazard community to address natural hazards in achieving the sustainable development goals.

Over time, there have been large leaps and advancements in our understanding of natural hazards and their management, facilitated, among others, by the following:

- The development and enhancement of physical, statistical, and numerical modelling of different natural hazards enable us to understand the processes behind the generation and propagation of natural hazards and characterisation of different natural hazards (OECD, 2012; Hirabayashi et al., 2013; Strauch et al., 2019).

- Increasing computational power allows for better, faster, and more complex modelling based on the higher spatial and temporal resolution of data (Ujjwal et al., 2019).

- Access to new and innovative data sources and data analysis techniques, such as remote sensing and Geographical Information Systems (GIS) (Gillespie et al., 2007; Poursanidis and Chrysoulakis, 2017) data and data generated through citizen science (Paul et al., 2018; Cochran et al., 2009).

- Systematic collection of parameters related to different natural hazards through the development of measurement technology (Angeli et al., 2000; Boiten, 2003; Herrmann et al., 2011).

- Understanding critical interaction of natural hazards with vulnerability shaped by social, economic, political, and cultural processes (O'Keefe et al., 1976; Cutter and Finch, 2008; Chmutina and von Meding, 2019), and with exposure (Lerner-Lam, 2007; Iglesias et al., 2021).

- The development of global policies to deal with disaster risks, the latest being the Sendai Framework for Disaster Risk Reduction 2015-2030 (UNISDR, 2015).

These advancements have been made possible due to scientific research across disciplines. This paper uses a broad classification of science, including natural sciences, engineering and technology, medical and health sciences, agricultural sciences, social sciences, and humanities (OECD, 2007). We also view research related to natural hazards and the reduction and management of related risks as inherently interdisciplinary (Peek and Guikema, 2021; Johnston and van de Lindt, 2022). Science is seen as key to policy-making for disaster risk reduction (Aitsi-Selmi et al., 2016a) and an imperative to meet a need for DRR (Shi et al., 2020). Science for DRR is crucial for understanding/characterising risk components (i.e., hazard, exposure, vulnerability), communicating disaster risk, and informing risk management and reduction options (JRC, 2017).

Despite increasing understanding of the importance of science in reducing disaster risks and undeniable scientific advancement, literature recognises many outstanding challenges in understanding hazards and risks and managing/reducing them (Albris et al., 2020; Shi et al., 2020). For instance, in their recent paper, (Cui et al., 2021) identify six frontier scientific issues:

- Hazard-formation mechanism due to multi-spherical interaction and identification of potential disaster risk, 
- Disaster mechanism corresponding to the coupling of endogenic and exogenic processes,

- Evolution of natural hazards and compound disaster chain generation,

- Temporal-spatial evolution of disaster risk,

- Theory of integrated disaster risk management, and

- Development of a resilient social model of harmony between man and nature.

Cui et al. (2021) also point out critical technological gaps, including monitoring and forecasting natural hazards, dynamic risk assessment, and comprehensive governance. Wartman et al. (2020) bring attention to significant challenges in modelling different natural hazards, decision-making under uncertainty, building community resilience, and mitigation of disaster risks. Similarly, Aitsi-Selmi et al. (2016a) agree on the gaps in hazard and risk modelling, but also identify a need for more efficient risk information sharing and capacity building across different stakeholders.

Overcoming these challenges and gaps can result in risk reduction and resilience building of people and nations, thus supporting the implementation of the SDGs. The SDGs comprise 17 global goals and were jointly agreed by 193 countries in

78 September 2015 (Aitsi-Selmi et al., 2016b). These goals serve as a blueprint for both developed and developing countries on how to create sustainable futures by 2030. According to the reflection paper by (UNDRR, 2015), there are 25 targets related to DRR in 10 out of 17 global goals. Consequently, a need for an enhanced understanding of how the natural hazard community can support the implementation of the SDGs is evident.

This paper is organised as follows: Section 2 presents our methodological approach, including survey design and 84 implementation, and thematic analysis of received responses. Section 3 presents our results, including the overview of survey respondents and an analysis of the response to the two questions. Section 4 discusses some of the findings, while in Section $\mathbf{5}$, we draw main conclusions.

\section{Methods}

This section describes our methodology for our survey design and implementation (Section 2.1) and then our data analysis (Section 2.2).

\subsection{Survey design and implementation}

The four executive editors of the journal Natural Hazards and Earth System Sciences (NHESS, https://nhess.copernicus.org/), and in the context of the 20th anniversary of the journal, designed the text for a questionnaire which was then placed in an online format using Google forms (see Appendix A) with the following three parts:

- Part 1. General introduction and how participant responses will be used 
- Part 2. Two questions, with space for open-ended answers:

a) Question $1(\mathrm{Q} 1)$. What are the top three scientific challenges you believe are currently facing our understanding of natural hazards?

b) Question 2 (Q2): What three broad step changes should or could be done by the natural hazard community to address natural hazards in achieving the sustainable development goals?

- Part 3. Identification preferences of the participants (i.e., their institution name and country, position, name).

102 A brief message advertising the NHESS questionnaire (along with its URL link), was then shared through (i) an e-mail to the mailing list of those affiliated with the EGU natural hazard division (1550 e-mails), (ii) an e-mail to the EGU NHESS author contact list (3085 e-mails, some which are no longer current), (iii) the EGU division Facebook page (994 people following), (iv) the EGU Natural Hazard division Twitter feed (1900 followers), and (v) some personal Twitter feeds. There is a clear overlap in the different methods being used. Still, we estimate that the advertising reached on the order of 3000 people, primarily natural scientists (including students), who self-identified as being part of the natural hazard community. The EGU contact lists based on contact authors of the NHESS publications are primarily European (71\%), but with a substantial minority from North America (13\%), Asia (12\%), and then fewer from other global regions (4\%) such as Africa and South America. The questionnaire was left open for two months, and in total, there were 350 responses.

\subsection{Data analysis}

Respondents' answers to Questions 1 and 2 were open-ended and qualitative, resulting in a rich data set. Upon the initial screening of the answers and understanding the diversity of community views, we analysed the data set using thematic analysis.

114 Thematic analysis is a commonly used method in analysing qualitative data, based on identifying, analysing, and reporting themes within data sets (Braun and Clarke, 2006). In our case, thematic analysis was beneficial for summarising large data sets and identifying key features (King, 2004). We had 350 diverse answers from respondents in different disciplines and geographical regions, presenting discipline and geography-focused views. Therefore, thematic analysis was an approach allowing us to come up with meaningful themes describing the data.

120 For the analysis, we used QSR NVivo version 1.5, a qualitative data software (NVivo, 2021). We chose to use this software for data analysis given the large amount of data collected, as it allowed for an accessible overview of data, coding process, and manipulation of sub-themes and themes. Paulus and Lester (2020) note that using software to analyse qualitative data allows for different data management options and leads to more efficient and effective analysis. Using software also allows the researcher to analyse a greater quantity of data, faster and more complexly (Robins and Eisen, 2017). 
- Started a coding process, with codes assigned to pieces of text, including words, phrases, sentences and paragraphs (Miles and Huberman, 1994).

- Codes were then merged into sub-themes and sub-themes into themes.

- We conducted the above separately for Questions 1 and 2.

Overall, in our thematic analysis, we employed the following six stages of thematic analysis as outlined by Nowell et al. (2017):

1. Familiarising yourself with the data: Upon uploading the data set to NVivo, we first explored the data through critical reading and understanding the most used phrases.

2. Generating initial codes: Initially, we created 58 codes for Question 1 and 38 codes for Question 2.

3. Searching for themes: Upon revising the codes and grouping them into sub-themes, followed by merging themes into sub-themes, we created 11 themes for Question 1 and 9 themes for Question 2.

4. Reviewing themes: The authors reviewed the themes in online meetings and re-grouped them into six themes for both questions.

5. Defining and naming themes: Similar to the above, all authors refined the names of the themes and defined what is included under each of the themes.

6. Producing the report: The results were written up and are presented in Section 3.

Upon finalising the thematic analysis in NVivo, we continued the analysis in Excel. One aspect we were interested in were regional perspectives. We first went through all information on institutions given by respondents and from each of these identified their region. Themes in NVivo were then expressed according to the percentage of total responses from the region.

\section{Results}

Section 2 elaborated on how we collected the responses and our general approach to the analysis. In this section, we begin by presenting respondents' demographics (Section 3.1), followed by an analysis of respondents' identification of top scientific challenges facing the natural hazards community (Section 3.2), and finally broad step changes needed in the natural hazards community to address the SDGs (Section 3.3).

\subsection{Overview of survey respondents}

In total, we received 350 responses. In terms of regional representation (Table 1), the majority of respondents were from European countries ( $n=201$ [57\%] out of 350), with Southern and Western Europe both showing the strongest response rates, followed by Asia $(n=38[11 \%])$ and North America $(n=25[7 \%])$. In contrast, there were fewer responses from the rest of the regions (South and Central America, Caribbean, Oceania and Africa), which we grouped together ( $n=27$ [7.7\%]. In 
addition, 59 respondents did not indicate their regional profile. The institutional profile of the participants is provided in Table 2 with the majority of respondents representing academia $(n=198[57 \%])$, national research centres, institutes and labs $(n=$ $48[14 \%])$, and governmental organizations $(n=29[8 \%])$.

162 Table 1: Overview of the regional profile of the $n=\mathbf{3 5 0}$ respondents to the NHESS questionnaire on challenges to our understanding of natural hazard challenges and step changes the natural hazard community might make in the context of the Sustainable Development Goals. The region as defined by United Nations (2021).

\begin{tabular}{|c|c|c|c|}
\hline Region & $\begin{array}{c}\# \\
\text { Respondent }\end{array}$ & $\begin{array}{l}\% \text { of } \\
\text { Total }\end{array}$ & Countries [\# respondents] \\
\hline Asia & 38 & $10.9 \%$ & $\begin{array}{l}\text { China [11], Japan [8], India [7], Turkey [3], Iraq [2], Israel [2], Nepal } \\
\text { [2], Georgia [1], Kazakhstan [1], Thailand [1] }\end{array}$ \\
\hline North America & 25 & $7.1 \%$ & United States [21], Canada [4] \\
\hline $\begin{array}{l}\text { S America, Central America, } \\
\text { Caribbean, Oceania and Africa }\end{array}$ & 27 & $7.7 \%$ & $\begin{array}{l}\text { Australia [5], Brazil [5], Colombia [4], Mexico [3], Chile [2], Ecuador [2], } \\
\text { New Zealand [2], Ethiopia [1], Egypt [1], Costa Rica [1], Cuba [1] }\end{array}$ \\
\hline Eastern Europe & 12 & $3.4 \%$ & Russia [4], Romania [3], Bulgaria [2], Poland [2], Czech Republic [1] \\
\hline Southern Europe & 90 & $25.7 \%$ & Italy [42], Spain [23], Greece [13], Portugal [6], Croatia [4], Slovenia [1] \\
\hline Northern Europe & 22 & $6.3 \%$ & United Kingdom [16], Norway [5], Sweden [1] \\
\hline Western Europe & 77 & $22.0 \%$ & $\begin{array}{l}\text { Germany [29], France [20], Switzerland [9], The Netherlands [7], } \\
\text { Belgium [6], Austria [6] }\end{array}$ \\
\hline Region not indicated & 59 & $16.9 \%$ & \\
\hline Total & 350 & $100 \%$ & \\
\hline
\end{tabular}

Table 2: Overview of the institutional profile of respondents

\begin{tabular}{lrr} 
Institution & \multicolumn{1}{c}{$\begin{array}{c}\text { \# } \\
\text { Respondent }\end{array}$} & $\begin{array}{r}\text { \% of } \\
\text { Total }\end{array}$ \\
University & 198 & $56.6 \%$ \\
National Research Centres, Institutes and Labs & 48 & $13.7 \%$ \\
Governmental Organization & 29 & $8.3 \%$ \\
International Organization & 6 & $1.7 \%$ \\
International Research Centre & 5 & $1.4 \%$ \\
Non-Governmental Organization & 1 & $0.3 \%$ \\
\hline Institution not indicated & 63 & $18.0 \%$ \\
\hline Total & 350 & $100.0 \%$ \\
\hline
\end{tabular}

168 We did not explicitly ask the respondents what hazards are their primary point of interest (either scientifically or practically). However, to gain some understanding of hazards of interest for respondents, we identified, in their answer to Question 1, 
instances when they explicitly mentioned specific hazards, as presented in Figure 1. In total, 123 out of 350 respondents explicitly mentioned a hazard. We used the following hazards grouping:

- geophysical hazards (earthquakes, landslides, tsunamis, volcanoes)

- hydrological hazards (floods, droughts, also includes water availability)

- $\quad$ atmospheric (cold and heat waves, hurricanes, sandstorms, cyclones, rain, hail, storms, tornadoes, typhoons)

- marine hazards (sea level rise, sea surges, waves, coastal flooding, saltwater intrusion, coastal retreat)

- biophysical (wildfires)

- environmental hazards (desertification, deforestation, environmental pollution, soil erosion, karstification, loss of biodiversity)
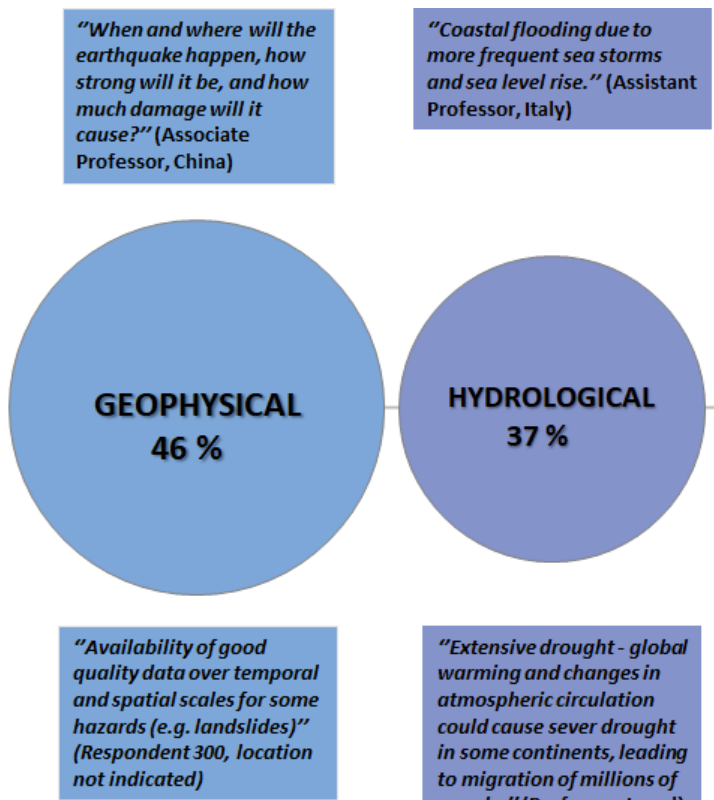

Figure 1: Major hazard groups identified by survey respondents in answer to Question 1, together with example quotes. The percentages have been determined out of the total number of respondents whose answers mentioned a hazard $(n=123)$, not all respondents $(n=350)$.

\subsection{Analysis of Question 1: Top three scientific challenges currently facing our understanding of natural hazards?}

186 Respondents' answers on the scientific challenges facing our understanding of natural hazards were grouped under six broad and distinct themes. Figure 2 provides an overview of the themes, indicating the percentage of respondents ( $\%$ out of $n=350$ ) whose answers were classified under this theme, as well as providing some example quotes. 


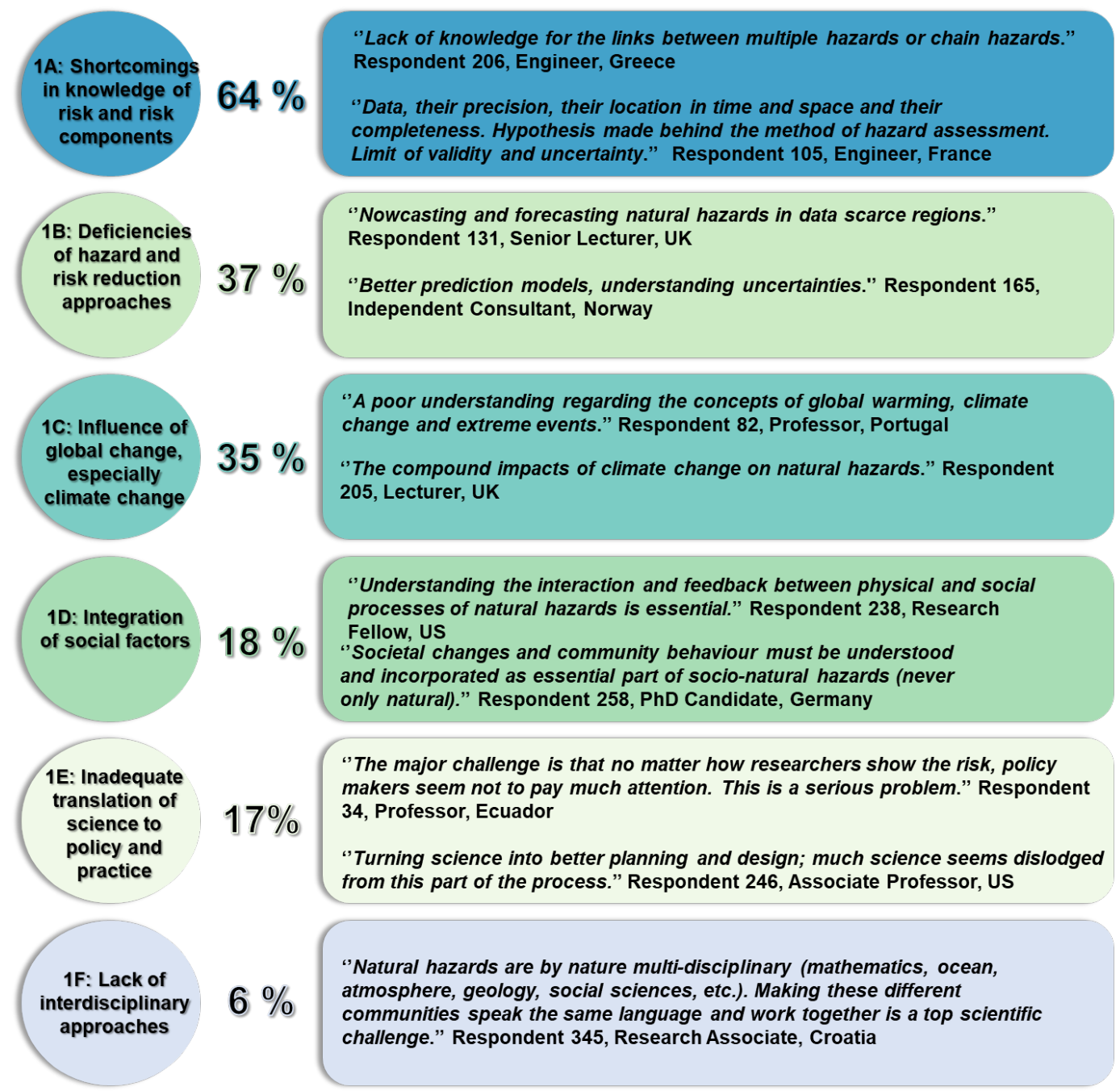

Figure 2: Six themes identified through thematic analysis of responses to the question "What are the top three scientific challenges you believe are currently facing our understanding of natural hazards?" along with example quotes. Percentages indicate the percentage of all respondents $(n=350)$ whose answers were classified under a given theme.

We now briefly describe each of the six themes for Question 1, including the main characteristics of the answers for each of the themes we chose, using thematic analysis in NVivo as described in Section 2.2.

\section{Q1. Theme 1A Shortcomings in knowledge of risk and risk components}

The largest proportion of participants' answers (64\% of 350 respondents) identified shortcomings in the knowledge of risk and risk components (i.e., hazard, exposure, vulnerability) as the most significant scientific challenge facing our understanding of 
natural hazards. The following were the main characteristics identified in respondent answers in terms of major gaps of knowledge:

- Major gaps in existing knowledge on the characterisation of different hazards (e.g., non-stationarity of natural hazards, choices of return periods, spatial-temporal patterns of extreme events, non-linearity of processes).

- Knowledge of vulnerability and exposure, especially their dynamics, remains limited. For instance, Respondent 96 (position, location not indicated) noted "understanding and modelling changes and dynamics in vulnerability" as a significant challenge.

- Lack of sophistication and accuracy of modelling approaches (e.g., current status of physics-based models, available methods for model validation, and characterisation of uncertainty in modelling). Modelling interactions of different risk components remains a challenge; as described by Respondent 135 (Professor, Belgium), "modelling co-evolution of hazard and socio-economic dynamics". Furthermore, respondents' answers pointed to the inadequacy of data informing the modelling process (e.g., inadequate spatial and temporal resolution of the existing datasets).

- A prominent gap in our understanding of risk and its components was identified as the lack of understanding of multihazards and multi-risk, especially the interrelationships between different hazards. Respondents identified cascading, compound, and triggering interrelationships. For example, Respondent 14 (Associate Professor, USA) pointed out that "cascading and overlapping events present challenges for traditional hazard planning".

- Finally, paucity in the characterisation of risk to impact pathways was noted, including different types of impact (e.g., impact on social systems).

\section{Q1. Theme 1B Deficiencies of hazard and risk management approaches}

Answers from $37 \%$ of the 350 respondents indicated that they see deficiencies of hazard and risk management approaches as

one of the key challenges faced by the natural hazards community. Primarily, this theme was dominated by describing deficiencies in current forecasting of natural hazards (e.g., validation of forecasts, forecasting models, forecast lead times) and especially forecasting of earthquakes (although other hazards such as floods, droughts, meteorological phenomena, and landslides were also indicated).

This theme also contained answers on the deficiencies in knowledge on various approaches to risk management. For instance,

Respondent 96 (position, location not indicated) identified as one of the key challenges "development and assessment of ecosystem-based approaches to disaster risk reduction and climate change adaptation", while some others felt that “operational and customised early warning systems" are missing (Respondent 188, Director, Cuba).

\section{Q1. Theme 1C Influence of global change, especially climate change}


Not surprisingly, $35 \%$ of the 350 respondents pointed to general gaps in understanding how various processes of global change influence natural hazards and vice versa. This predominantly focused on climate change, but also included land-use change, urbanisation, and population growth (with the latter three influencing exposure to natural hazards).

For climate change, respondents pointed out gaps in our understanding of climate change impacts on the frequency and magnitude of natural hazards, how climate change will influence their spatio-temporal behaviour, and various uncertainties augmented by climate change (e.g., in modelling hazard scenarios).

\section{Q1. Theme 1D Integration of social factors}

Answers from $18 \%$ of the 350 respondents indicated that social-aspects of hazard and risk management are not fully integrated into natural hazards risk analysis; for instance, our current ability to integrate human-related factors into modelling processes, as emphasised by Respondent 18 (Associate Professor, USA) “Our understanding of and ability to model feedbacks in coupledhuman natural systems." Further comments indicated that the natural hazards community recognised that current hazard and risk analysis lacks integration of risk perception, local and indigenous knowledge systems, and the overall consideration of inequality in understanding the risks of natural hazards.

\section{Q1. Theme 1E Inadequate translation of science to policy and practice}

Interestingly, $17 \%$ of the 350 respondents also recognised that the challenge might not be in our understanding of natural hazards, but rather in the inadequacy in the way science is communicated and scientific knowledge transferred to different stakeholders, including gaps in science-policy interface (SPI) and translation of research findings to practical approaches. For instance, many responses classified under this theme were concerned with how to communicate scientific information to a vast array of stakeholders, with communication challenges also including how we communicate forecasts and warnings.

Furthermore, respondents drew attention to several aspects related to the interface of science, policy and practice. These included the scientific community not having policy experience; science not "infiltrating" policy and decision-making spaces and informing policy design; research findings not informing and being translated to practical implementation.

\section{Q1. Theme 1F Lack of interdisciplinary approaches}

The final theme comprises $6 \%$ of the 350 respondents, who pointed out that although natural hazards and disaster risk reduction are per se interdisciplinary, there is a lack of interdisciplinary research, approaches, and professional capacity. 
https://doi.org/10.5194/nhess-2022-55

Preprint. Discussion started: 23 February 2022

(c) Author(s) 2022. CC BY 4.0 License.

(c) (i)

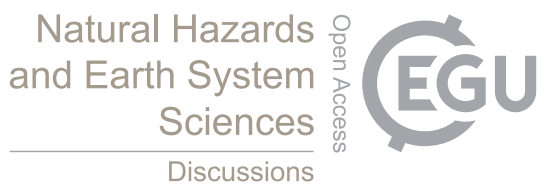

\subsection{Analysis of Question 2: Three broad step changes that should or could be done by the natural hazard community}

\section{to address natural hazards in achieving the sustainable development goals}

In the previous section, we presented challenges identified by the natural hazards community in our understanding of natural hazards and related risks. This section describes what broad step changes identified by the 350 respondents that the natural hazards community could do to address natural hazards in achieving the Sustainable Development Goals (SDGs).

Before addressing the suggested changes identified, we were interested in understanding the percentage of respondents' answers which explicitly referred to a specific SDG or could be inferred to refer to a specific SDG. Out of 350 respondents, 188 (54\%) mentioned one or more SDGs, either explicitly by name/number or we interpreted it from the answer they gave to Question 2. Figure 3 shows the results (out of 188) for the 17 SDGs identified by participants. The majority of responses ( $40 \%$ of 188) referred to the natural hazard community contribution to the implementation of the SDG 13: Climate Action, followed by SDG 11: Sustainable Cities and Communities (25\%), SDG 17: Partnership for the Goals (24\%), and Quality Education (24\%). Five other SDGs (SDG 15, SDG 1, SDG 9, SDG 10, and SDG6) had 10-13\% of participants referring to them, while

8 SDGs were referred to by $2-9 \%$ of respondents.

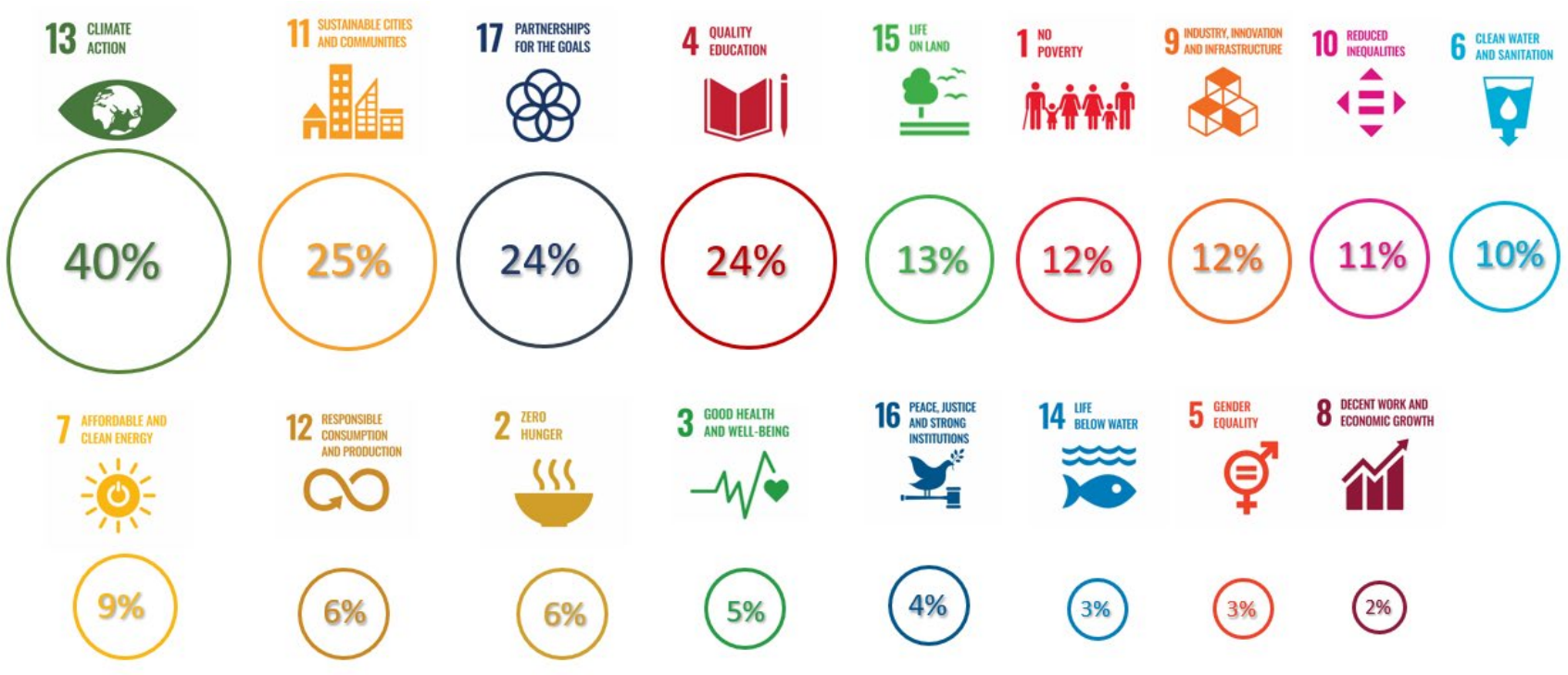

Figure 3: Percentage of respondents out of 188 referring to specific sustainable development goals (SDG) in response to the question on broad step changes that the natural hazards community could make to achieve the SDGs. The percentages have been determined out of the total number of respondents that specified an SDG $(n=188)$, not all respondents $(n=350)$. 
Respondents' answers on the broad changes needed in the natural hazards community to contribute to SDG implementation were grouped under six broad and distinct themes. Figure 4 provides an overview of the themes, indicating the percentage of respondents ( $\%$ out of $n=350$ ) whose answers were classified under each theme, as well as providing example quotes.

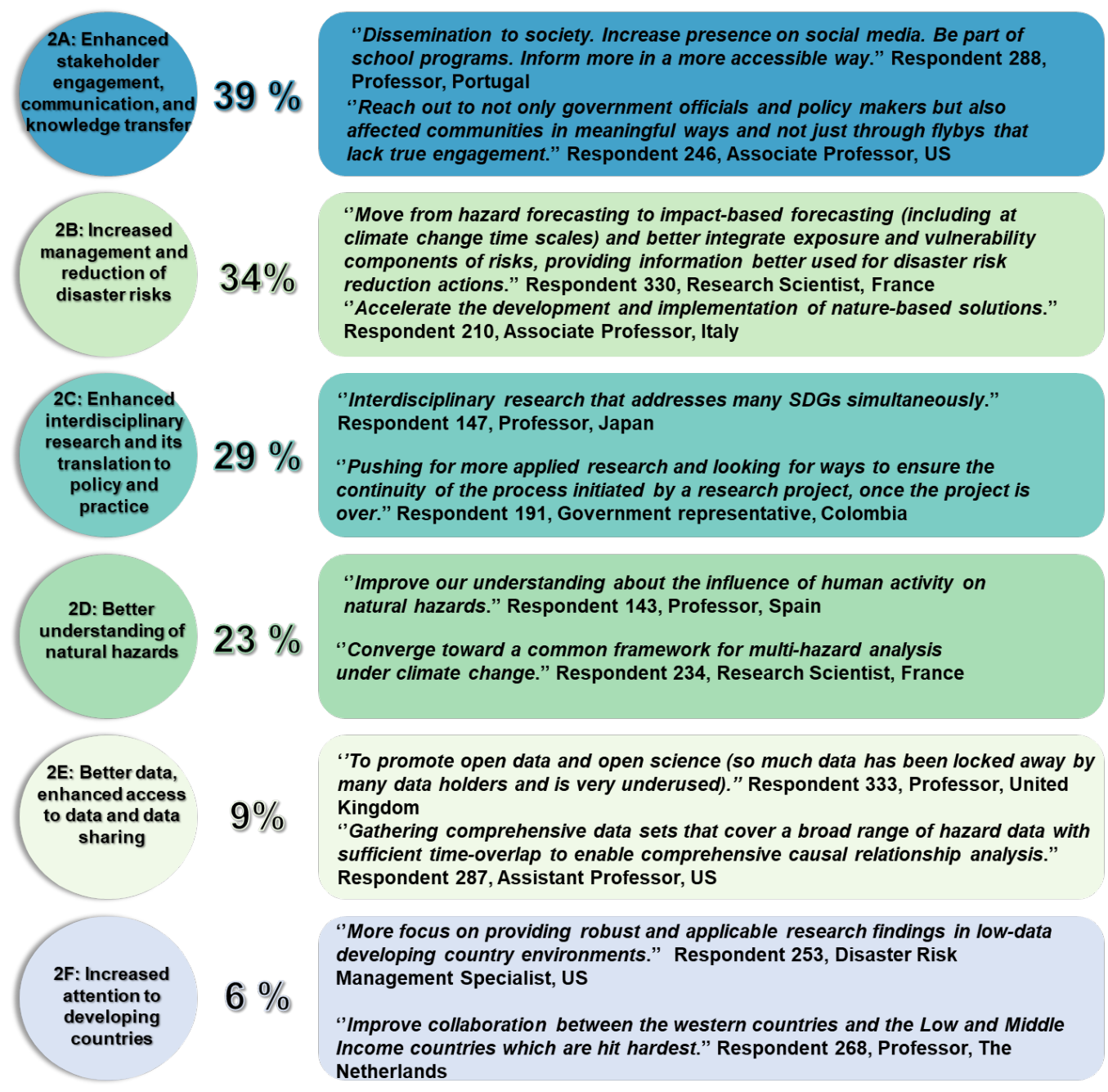

288 Figure 4: Six themes identified through thematic analysis of responses to the question "What three broad step changes should or could be done by the natural hazard community to address natural hazards in achieving the sustainable development goals?" along with example quotes. Percentages indicate the percentage of all respondents $(n=350)$ whose answers were classified under a given theme.

We now briefly describe each of the six themes for Question 2, including the main characteristics of the answers for each of the themes we chose, using thematic analysis in NVivo as described in Section 2.2. 


\section{Q2. Theme 2A Enhanced stakeholder engagement, communication, and knowledge transfer}

The largest theme (39\% of 350 respondents) refers to answers identifying a need for enhanced, better and active participation of different stakeholder groups in research activities and decision-making (e.g., involvement of communities at risk in the design of DRR strategies, collaboration with decision-makers in policy making). For example, Respondent 175 (Associate Professor, Italy) thought there is a need for "getting [scientists] more involved in the decision-making process."

This theme also emphasises a need to communicate science and scientific findings to the general public and other actors. This involved research in risk communication and facilitation of knowledge transfer horizontally (e.g., between scientific disciplines) and vertically (from scientists to other stakeholders, and local communities "upwards").

306 Finally, respondents felt an urgency to increase risk awareness in communities at risk and general education of the public on the topic of risks of natural hazards. For example, Respondent 141 (Associate Professor, Brazil) pointed out a need for "active participation of communities in understanding the phenomena associated with disasters." Further practical advice given by respondents was to introduce natural hazards education in schools, do public outreach and education, and design educational programmes focused on natural hazards.

\section{Q2. Theme 2B Increased management and reduction of disaster risks}

A total of $34 \%$ of 350 respondents provided answers focusing on a need to improve the way risks of natural hazards are managed and reduced. The largest sub-theme was an urgency for enhanced monitoring and forecasting of natural hazards. For example:

- More accurate forecasts with a shorter lead time

- Establishment of global monitoring and early warning systems

- Calls for hazard-specific forecasting (e.g., for seasonal drought prediction, earthquake forecasting)

Under this theme, respondents also called for improvements in various approaches to managing hazards and risks beyond mere forecasting and monitoring. These include, for instance, enhanced understanding of nature-based solutions, "more consideration of natural hazards in spatial and urban planning” (Respondent 266, Research Scientist, Australia), and "combination of structural and non-structural measures [...] to achieve the SDGs." (Respondent 238, Research Fellow, USA).

\section{Q2. Theme 2C Enhanced interdisciplinary research and its translation to policy and practice}

Based on answers from $29 \%$ of 350 participants, this theme summarises calls for more research that will facilitate filling in of identified knowledge gaps and calls for increased research funding. Special attention was given to calls for interdisciplinarity and multidisciplinarity (e.g., removing the siloes of scientific disciplines and encouraging more collaboration between disciplines). Some examples include: 
- Interdisciplinary research addressing multiple SDGs simultaneously

- Interdisciplinary postgraduate studies

Also, respondents identified an urgent need for research to be better translated to policy and practice (e.g., bridging between the scientific community, practitioners, and decision-makers). For instance, Respondent 113 (Professor, Italy) pointed to a need to "enhance the transfer of scientific results into concrete actions." Further examples of solutions proposed by respondents included:

- Creation of basic services based on robust research findings

- Creation of decision support environments informed by the latest research

- Research informing government policies and practice

- Need for applied research

\section{Q2. Theme2 D Better understanding of natural hazards}

A total of $23 \%$ of 350 respondents identified a need to enhance our understanding of various aspects of natural hazards (e.g., spatio-temporal characterisation of natural hazards, a common definition of hazard magnitudes and frequencies). This theme also includes respondents who proposed the following solutions by the natural hazard community in achieving the SDGs:

- Enhancement of hazard analysis methodologies (e.g., understanding changes in natural hazards), modelling of natural hazards and associated uncertainties (e.g., increasing computation skills, black swan phenomenon, use of new technologies in natural hazard modelling)

- Characterisation of multi-hazards (e.g., assessments of multi-risks, hazard interrelationships)

- Inclusion of social factors in understanding hazards (e.g., understanding resilience, inequality consideration in risk understanding).

\section{Q2. Theme 2E Better data, enhanced access to data and data sharing}

354 There were $9 \%$ of 350 respondents who saw a way forward in achieving the SDGs by better data for characterisation and modelling of natural hazards, including a need to utilise emerging areas of data research such as big data. The theme also reflects calls for open data and data sharing between different scientific communities and geographies, as reflected in the answer by Respondent 250 (Senior scientist, Switzerland): "Open all environmental monitoring and observation data for everybody and any purpose as soon as possible after acquisition."

\section{Q2. Theme 2F Increased attention to developing countries.}

Finally, $6 \%$ of 350 respondents drew attention to the fact that there needs to be an enhanced focus on understanding natural hazards in the context of developing countries. This includes more research on natural hazards in these contexts and more collaboration with partners from the Global South. 


\subsection{Some reflections on regional differences in answers to Questions 1 and 2}

This section examines regional differences in the response percentages to Questions 1 and 2, noting that observed differences are marginal due to relatively low responses in each regional category. Using the eight regional categories presented in Figure 1, Table 3a presents the regional responses to Q1 on the top challenges facing our understanding of natural hazards. Table $3 \mathrm{~b}$ presents the regional responses to Q2 on the step changes recommended by the natural hazards community to address natural hazards in achieving the SDGs.

Table 3. Regional difference in responses to (a) Q1 Top challenges facing our understanding of natural hazards and (b) step changes to address natural hazards in achieving the sustainable development goals (SDGs). Expressed as the percentage of a total number of respondents in a region whose answers were classified under a specific theme.

\begin{tabular}{|c|c|c|c|c|c|c|c|}
\hline & \multirow[b]{2}{*}{$\begin{array}{l}\text { (a) Q1. Top challenges facing our } \\
\text { understanding of natural hazards }\end{array}$} & \multicolumn{6}{|c|}{ THEMES IDENTIFIED (expressed in percentages per region) } \\
\hline & & $\begin{array}{c}\text { 1A: } \\
\text { Shortcomings in } \\
\text { knowledge of } \\
\text { risk and risk } \\
\text { components } \\
\end{array}$ & $\begin{array}{l}\text { 1B: Deficiencies } \\
\text { of hazard and } \\
\text { risk reduction } \\
\text { approaches }\end{array}$ & $\begin{array}{l}\text { 1C: Influence of } \\
\text { global change, } \\
\text { especially } \\
\text { climate change }\end{array}$ & $\begin{array}{c}\text { 1D: Social } \\
\text { factors not fully } \\
\text { considered in } \\
\text { natural hazards } \\
\text { risk analysis }\end{array}$ & $\begin{array}{c}\text { 1E: Inadequate } \\
\text { translation of } \\
\text { science to policy } \\
\text { and practice }\end{array}$ & $\begin{array}{c}\text { 1F: Lack of } \\
\text { interdisciplinary } \\
\text { approaches }\end{array}$ \\
\hline \multirow{11}{*}{$\begin{array}{l}z \\
\text { 음 } \\
\underset{\sim}{\not{x}}\end{array}$} & Asia $(n=38)$ & $37 \%$ & $26 \%$ & $37 \%$ & $16 \%$ & $8 \%$ & $11 \%$ \\
\hline & North America $(n=25)$ & $72 \%$ & $40 \%$ & $40 \%$ & $12 \%$ & $28 \%$ & $4 \%$ \\
\hline & 27) & $81 \%$ & $44 \%$ & $26 \%$ & $7 \%$ & $11 \%$ & $11 \%$ \\
\hline & Eastern Europe $(n=12)$ & $8 B \%$ & $42 \%$ & $25 \%$ & $33 \%$ & $17 \%$ & $8 \%$ \\
\hline & Southern Europe $(n=90)$ & $58 \%$ & $44 \%$ & $40 \%$ & $20 \%$ & $19 \%$ & $7 \%$ \\
\hline & Northern Europe $(n=22)$ & $73 \%$ & $45 \%$ & $50 \%$ & $18 \%$ & $27 \%$ & $5 \%$ \\
\hline & Western Europe $(n=77)$ & $69 \%$ & $35 \%$ & $32 \%$ & $17 \%$ & $10 \%$ & $3 \%$ \\
\hline & Unassigned $(n=59)$ & $64 \%$ & $27 \%$ & $27 \%$ & $20 \%$ & $24 \%$ & $7 \%$ \\
\hline & Average across regions & $67 \%$ & $38 \%$ & $35 \%$ & $18 \%$ & $18 \%$ & $7 \%$ \\
\hline & \begin{tabular}{|l|} 
Standard deviation across regions \\
\end{tabular} & $15 \%$ & $8 \%$ & $9 \%$ & $8 \%$ & $8 \%$ & $3 \%$ \\
\hline & Percentage of total respondents $(n=350)$ & $64 \%$ & $37 \%$ & $35 \%$ & $18 \%$ & $17 \%$ & $6 \%$ \\
\hline
\end{tabular}

(b) Q2. Step changes to address natural hazards in achieving the SDGs

From Table 3a, we observe that for Question 1, on the top challenges facing our understanding of natural hazards, most regions generally had higher percentages of responses in A, followed by B and C, with similar values within each theme for most regions. The exception was Asia, which had a much lower response to Theme A compared to other regions, with Theme $\mathrm{C}$ being a similar value. It is noteworthy that these Themes A to $\mathrm{C}$ are primarily concerned with an absence of physical scientific knowledges and were identified by most participants as being key challenges. This is compared to the relatively few responses 
classified under Themes D to F, that noted the importance of social factors, policy issues or interdisciplinary approaches in their responses to this question.

Most responses to Question 2 (Table 3b) were coded in themes A and B across the regions. Relatively few respondents suggested the need for Theme F, increased attention to developing countries, but those that did tended to be either from the region of South and Central America, Caribbean, Oceania, Africa or within Western Europe. North American respondents tended not to note issues with data (Theme E). Interdisciplinary working (Theme C) was noted by slightly fewer people in Eastern and Northern Europe. We also observe that although a relatively low percentage (average 7\%) noted lack of interdisciplinary approaches as a challenge in Q1 (Table 3a, Theme F), a much larger percentage (average 29\%) identified the need for interdisciplinary research to address natural hazards in the context of the SDGs in Q2 (Table 3b, Theme C).

\section{Discussion}

Through thematic analysis of 350 responses to two questions, we identified some views of the natural hazards community on the scientific challenges facing our understanding of natural hazards (Section 3.2) and broad changes needed to support the implementation of the SDGs (Section 3.3).

396 We found that challenges are many and cut across different scientific disciplines and fields of expertise. The challenges identified in our work align well with challenges identified in the literature (e.g., Aitsi-Selmi et al., 2016b; Wartman et al., 2020; Cui et al., 2021). However, our analysis was based on responses from a wider natural hazard community $(n=350)$ compared to previous studies, thus representing views of diverse types of stakeholders that make up the natural hazard community, including researchers, academics, and representatives of the governmental organisations. For instance, Cui et al. (2021) based their findings on a systematic analysis of literature, similar to Shi et al. (2020). Other studies report findings 402 based on the analysis of stakeholders' responses, but more focused. For example, Freddi et al. (2021) focus on the views of the earthquake disaster risk reduction community, while Wartman et al. (2020) present the views of the reconnaissance community.

We see that many challenges identified by our respondents are timely and in line with big scientific questions that the natural hazards community is currently facing. For instance, Theme D (Integration of Social Factors) also includes calls for further understanding of the interaction between human societies and natural hazards, a theme covered in growing fields like sociohydrology (e.g., Di Baldassarre et al., 2013; Mazzoleni et al., 2021). Similarly, there are growing calls for increased understanding of multi-hazards and their interrelationships, a topic of increased focus within the scientific community (e.g., Gill and Malamud, 2014; de Ruiter et al., 2020; Ward et al., 2021; Kreibich et al., 2021). 
Although our Question 1 focused on scientific challenges facing understanding of natural hazards, answers provided by 414 respondents go beyond natural hazards and towards more holistic risk-thinking and existing gaps (e.g., in terms of risk reduction approaches, inadequate translation of science to policy and thinking, lack of inclusion of social factors). Thus, the major theme for Question 1 is "Shortcomings in knowledge of risk and risk components", where participants identified existing knowledge gaps not only of hazard processes but also in terms of our understanding of vulnerability, exposure, and impact. This might suggest a need for greater engagement between the natural hazards community and the social sciences.

Moreover, although challenges identified in Question 1 are often of a more "technical" and "scientific" nature (e.g., hazard forecasting, modelling approaches), answers to Question 2 and major themes emerging had a slightly different focus. For instance, according to our respondents, the major step forward was an identified need for enhanced stakeholder engagement, communication, and knowledge transfer. This was closely followed by a shift towards the actual reduction and management of disaster risks (e.g., through nature-based solutions, impact-based forecasting), interdisciplinary research and its translation to policy and practice. This change of focus from "technical" and "scientific" to "managerial" and "governance-oriented" shows that respondents felt that, for the natural hazards community to enhance the implementation of the SGDs, is not necessarily about the next scientific break-through, but about overcoming common obstacles in the delivery of DRR (e.g., topdown approaches, lack of engagement with different stakeholders, and policy and practice not informed by science) which are beyond just scientific realm.

Our findings on the way forward indicate that the natural hazards community can contribute to all 17 SDGs. Most writings on the connection between disaster risk reduction and SDGs identify fewer links. For instance, UNDRR (2015) sees ties in 10 of 17 SDGs, while Izumi et al. (2020) identify linkages with 15 SDGs. It is apparent from our findings that natural hazard communities see their role in each of the SDGs, both in terms of research (e.g., characterising links between climate change and natural hazards), but also in terms of delivering concrete solutions to challenges tackled by SDGs (e.g., nature-based solutions for climate change mitigation and adaptation). This is consistent with the suggestions of articles within Gill and Smith (2021).

It is especially interesting to see a clear recognition of the importance of interdisciplinary research on natural hazards in achieving the SDGs. It is widely accepted that challenges related to sustainable development cannot be solved under the realm of any specific discipline. For instance, this has previously been discussed in research on health (Van Wees et al., 2019), geosciences (Gill and Bullough, 2017; Gill and Smith, 2021) and land use (Johansen et al., 2020). Our results suggest the same for the natural hazards community. Gill and Smith (2021) contain articles that give examples of how the geosciences more 444 broadly relate to the SDGs, including work on natural hazards (e.g., Gill et al., 2021; Smith and Bricker, 2021). 
But as identified by natural hazard community members, it is crucial how to translate this research to policy and practice. Challenges to implementing the SDGs are many; for instance, addressing different SDGs in parallel and limited financial resources in developing countries (Akenroye et al., 2018). Leal Filho et al. (2021) identify a lack of policies, proper governance, financial resources, training programmes and trained personnel as key challenges in this area.

Taken together, responses to both questions suggest that while there are many important technical and scientific challenges around the forecasting and understanding of natural hazards, there are also felt gaps in the integration of natural hazards knowledge with other disciplines, such as the social sciences and also their integration beyond the academy. This points to a desire for more robust and effective transdisciplinary approaches to ensure that disaster science is "useful, usable and used" (Boaz and Hayden, 2002; Aitsi-Selmi et al., 2016a).

The limitations of this research are primarily connected to the respondent profiles and analysis method. As presented in Section 3.1, respondents were primarily from Europe, with a significantly lower representation from other regions. Therefore, it is essential to acknowledge that the views represented could be biased towards the views of European participants and that an increased number of respondents from other regions would quite possibly modify the themes. Furthermore, $16.9 \%$ of respondents did not indicate their region, and $18.0 \%$ did not indicate their institutions. Finally, NHESS is a journal with a predominant focus on physical science, meaning that the views of, for instance, social scientists, were not captured extensively in our analysis. The results would likely have been very different, for example, had this survey gone to a broader community of disaster risk researchers, which might include additional social, medical and agricultural scientists as well as a broader range of practitioners.

We have used thematic analysis, which is ultimately a subjective analysis method, albeit widely used in qualitative data analysis. It depends on researchers' positionality (e.g., epistemological and ontological stance). The group discussion of the themes and the dataset makes it intersubjective, and we acknowledge that a different set of authors would likely have come up with slightly different themes. However, group discussion of the themes also served as a way to reduce the subjectivity and come up with agreed themes that would represent the diversity of data. Answers from participants were very diverse, and in the majority of cases, the answers were concise. Therefore, it was a challenge to develop really "strict" themes with "impermeable" boundaries. Although the identified themes were quite broad, they still conveyed the main priorities identified 474 by respondents and depict the richness and diversity of inputs.

\section{Conclusions}

In this paper, we have presented the natural hazards community views on the most significant scientific challenges regarding natural hazards and the broad changes needed to contribute to the implementation of the SDGs. To examine the natural hazards 
community views, we have used thematic analysis of the responses from 350 natural hazard scientists, government workers, and practitioners. We have classified the responses for each of the two questions into six themes. According to the 350 respondents, the most significant challenges are the following: (i) shortcomings in the knowledge of risk and risk components, (ii) deficiencies of hazard and risk reduction approaches, (iii) influence of global change, especially climate change, (iv) integration of social factors, (v) inadequate translation of science to policy and practice, and (vi) lack of interdisciplinary approaches. In order for the natural hazard community to support the implementation of SGDs, respondents called for: (i) enhanced stakeholder engagement, communication, and knowledge transfer, (ii) increased management and reduction of disaster risks, (iii) enhanced interdisciplinary research and its translation to policy and practice, (iv) a better understanding of natural hazards, (v) better data, enhanced access to data and data sharing, and (vi) increased attention to developing countries.

The results of the thematic analysis point to scientific challenges within the natural hazard community that remain numerous and cut across scientific disciplines and topics of interest. Identified challenges in this paper could provide valuable and useful insights for further research and inform tailored research funding. As for the natural hazard community supporting the SDG implementation, our analysis shows that scientific advancements are just a part of the solution, while primary changes are needed in the way risks are governed (e.g., who gets a chance to participate and how is knowledge transferred) and how science informs policy and practice. 


\title{
Appendices:
}

\section{Appendix A Online Survey Form}

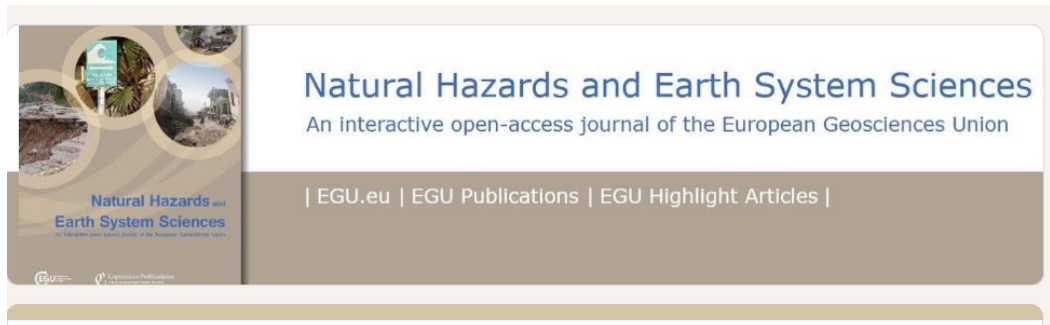

\section{Two Questions for the Natural Hazards Community}

\begin{abstract}
As part of the Natural Hazards and Earth System Sciences (NHESS) journal's 20th-anniversary activities, we are approaching the natural hazards $(\mathrm{NH})$ community to ask your expert opinion on the following:

(i) three challenges facing our understanding of natural hazards; (ii) three broad step changes to address natural hazards in achieving the sustainable development goals.

NHESS is one of 19 open access interactive journals of the European Geosciences Union: https://www.natural-hazards-and-earth-system-sciences.net/. This questionnaire has been put together by the four NHESS Executive editors (Heidi Kreibich, Paolo Tarolli, Uwe Ulbrich and Bruce D Malamud) on behalf of the NHESS editorial board.
\end{abstract}

How we will use your responses.

We will use your replies in one of two ways depending on the number and richness of the replies from the $\mathrm{NH}$ community:

(1) We will create a synthesise across all responses (all responses anonymous).

(2) Some or all individual responses posted as part of a publication in NHESS as partial or full quotes.

If quoted responses, you have a choice of whether you allow for us to use some combination of (a) your institution name, (b) job title, (c) your name, or completely anonymous. After the two questions, there

will be a location for you to fill in your details.

Figure A1. First part of the online survey form for the NHESS Questionnaire in Google Forms. 
https://doi.org/10.5194/nhess-2022-55

Preprint. Discussion started: 23 February 2022

(c) Author(s) 2022. CC BY 4.0 License.

Two Questions for You

Q1. What are the top three scientific challenges you believe are currently facing our understanding of natural hazards?

Please give THREE bullet points, each 1 to 20 words. This box will expand.

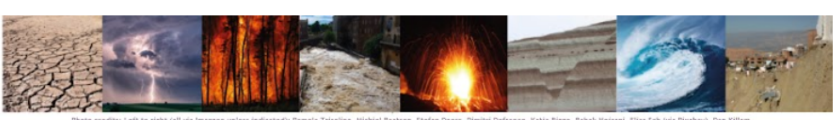

Your answer

Q2. What three broad step changes should or could be done by the natural hazard community to address natural hazards in achieving the sustainable development goals?

Please give THREE bullet points, each 1 to 20 words. This box will expand
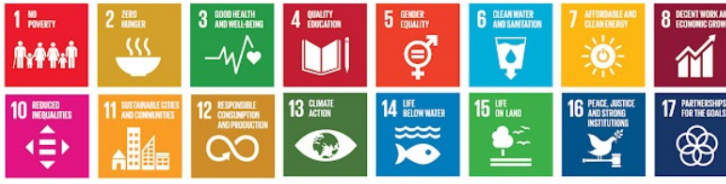

Your answer

(a) Your full institution name and country (IF YOU ALLOW IT TO BE USED IN QUOTED MATERIAL) (e.g., German Research Centre for Geosciences, Germany; University of Padua, Italy)

Your answer

(b) Your job title (IF you ALLOW It to BE USED IN QuOTEd MATERIAL) (e.g., Research Geophysicist Scientist, Professor of Hydrology, PhD student in atmospheric sciences)

Your answer

(c) Your name (IF You ALLoW IT to be USEd IN QUOTED MATERIAL)

Your answer

Figure A2. Second (and final) part of the online survey form for the NHESS Questionnaire in Google Forms. 
504 - Data availability We provide as supplementary material an Excel file with the questionnaire (Appendix A) raw data for the 350 respondents, with respondent names and institutions removed. The data are classified according to two questions and answers are split into three columns for each of the two questions. The Excel file also contains information on each respondent's job title, along with our interpretation (based on their institution name, not given in this Excel sheet) of their institution type, country and region.

\section{- Video supplement}

510 - Supplement link: the link to the supplement will be included by Copernicus, if applicable.

- Author contribution: RST, BDM, and AD designed the methodology. RST conducted the formal analysis with inputs and regular discussions with BDM and AD. RST took the lead on preparing the original draft with BDM and AD contributing, and then all authors jointly reviewed and edited.

- Competing interests: Authors BDM and ARD are members of the editorial board of NHESS. The peer-review process was guided by an independent editor, and the authors also have no other competing interests to declare."

\section{$516 \bullet$ Disclaimer}

- Special issue statement: the statement on a corresponding special issue will be included by Copernicus, if applicable.

- Acknowledgements: The authors thank the following NHESS executive editors who, together with author BDM, helped with questionnaire development and dissemination: Heidi Kreibich (GFZ), Uwe Ulbrich (Freie Universität Berlin) and Paolo Tarolli (University of Padua). We also gratefully acknowledge all respondents in the natural hazards community for taking the time to fill in the questionnaire and provide data for this study. 


\section{References}

Aitsi-Selmi, A., Blanchard, K., and Murray, V.: Ensuring science is useful, usable and used in global disaster risk reduction and sustainable development: a view through the Sendai framework lens, Palgrave Commun., 2, 1-9, https://doi.org/10.1057/palcomms.2016.16, 2016a.

Aitsi-Selmi, A., Murray, V., Wannous, C., Dickinson, C., Johnston, D., Kawasaki, A., Stevance, A.-S., and Yeung, T.:

528 Reflections on a Science and Technology Agenda for 21st Century Disaster Risk Reduction, Int J Disaster Risk Sci., 7, 1-29, https://doi.org/10.1007/s13753-016-0081-x, 2016b.

Akenroye, T. O., Nygård, H. M., and Eyo, A.: Towards implementation of sustainable development goals (SDG) in developing nations: A useful funding framework, International Area Studies Review., 21, 3-8, https://doi.org/10.1177/2233865917743357, 2018.

Albris, K., Lauta, K. C., and Raju, E.: Disaster Knowledge Gaps: Exploring the Interface Between Science and Policy for 534 Disaster Risk Reduction in Europe, Int J Disaster Risk Sci., 11, 1-12, https://doi.org/10.1007/s13753-020-00250-5, 2020.

Angeli, M.-G., Pasuto, A., and Silvano, S.: A critical review of landslide monitoring experiences, Eng Geol., 55, 133-147, https://doi.org/10.1016/S0013-7952(99)00122-2, 2000.

Boaz, A., and Hayden, C.: Pro-active evaluators: enabling research to be useful, usable and used, Evaluation-US., 8(4), 440453, https://doi.org/10.1177/13563890260620630, 2002.

Boiten, W.: Hydrometry: IHE Delft Lecture Note Series, CRC Press, London, $256 \quad$ pp., 540 https://doi.org/10.1201/9780203971093, 2003.

Braun, V. and Clarke, V.: Using thematic analysis in psychology, Qual Res Psychol., 3, 77-101, https://doi.org/10.1191/1478088706qp063oa, 2006.

Chmutina, K. and von Meding, J.: A Dilemma of Language: "Natural Disasters" in Academic Literature, Int J Disaster Risk Sci., 10, 283-292, https://doi.org/10.1007/s13753-019-00232-2, 2019.

Cochran, E. S., Lawrence, J. F., Christensen, C., and Jakka, R. S.: The Quake-Catcher Network: Citizen Science Expanding

546 Seismic Horizons, Seismol Res Lett., 80, 26-30, https://doi.org/10.1785/gssrl.80.1.26, 2009.

Coronese, M., Lamperti, F., Keller, K., Chiaromonte, F., and Roventini, A.: Evidence for sharp increase in the economic damages of extreme natural disasters, PNAS., 116, 21450-21455, https://doi.org/10.1073/pnas.1907826116, 2019.

Cui, P., Peng, J., Shi, P., Tang, H., Ouyang, C., Zou, Q., Liu, L., Li, C., and Lei, Y.: Scientific challenges of research on natural hazards and disaster risk, Geography and Sustainability., 2, 216-223, https://doi.org/10.1016/j.geosus.2021.09.001, 2021.

Cutter, S. L. and Finch, C.: Temporal and spatial changes in social vulnerability to natural hazards, PNAS., 105, 2301-2306, 552 https://doi.org/10.1073/pnas.0710375105, 2008.

de Ruiter, M. C., Couasnon, A., van den Homberg, M. J. C., Daniell, J. E., Gill, J. C., and Ward, P. J.: Why We Can No Longer Ignore Consecutive Disasters, Earth's Future., 8, e2019EF001425, https://doi.org/10.1029/2019EF001425, 2020. 
Di Baldassarre, G., Viglione, A., Carr, G., Kuil, L., Salinas, J. L., and Blöschl, G.: Socio-hydrology: conceptualising humanflood interactions, Hydrol Earth System Sc., 17, 3295-3303, https://doi.org/10.5194/hess-17-3295-2013, 2013.

Freddi, F., Galasso, C., Cremen, G., Dall'Asta, A., Di Sarno, L., Giaralis, A., Gutiérrez-Urzúa, F., Málaga-Chuquitaype, C., Mitoulis, S. A., Petrone, C., Sextos, A., Sousa, L., Tarbali, K., Tubaldi, E., Wardman, J., and Woo, G.: Innovations in earthquake risk reduction for resilience: Recent advances and challenges, Int J Disast Risk R., 60, 102267, https://doi.org/10.1016/j.jidrr.2021.102267, 2021.

Gill, J.C. and Bullough, F. Geoscience engagement in global development frameworks. Annals of Geophysics., 60, 2017.

Gill, J.C. and Malamud, B.D.: Reviewing and visualising the interactions of natural hazards. Rev Geophys., 52(4), 680-722, https://doi.org/10.1002/2013RG000445, 2014.

564 Gill, J.C. and Smith, M. Geosciences and the Sustainable Development Goals. Springer, 2021.

Gill, J.C., Barich, A., Bilham, N., Caven, S., Donovan, A., Ruiter, M.D. and Smith, M.: Peace, Justice, and Strong Institutions. In Geosciences and the Sustainable Development Goals (pp. 393-421). Springer, Cham., 2021.

Gillespie, T. W., Chu, J., Frankenberg, E., and Thomas, D.: Assessment and prediction of natural hazards from satellite imagery, Prog Phys Geog., 31, 459-470, https://doi.org/10.1177/0309133307083296, 2007.

Glasser, R.: The Climate Change Imperative to Transform Disaster Risk Management, Int J Disaster Risk Sci., 11, 152-154, 570 https://doi.org/10.1007/s13753-020-00248-z, 2020.

Herrmann, R. B., Benz, H., and Ammon, C. J.: Monitoring the Earthquake Source Process in North America, Seismol Soc Am., 101, 2609-2625, https://doi.org/10.1785/0120110095, 2011.

Herzig Van Wees, S. L., Målqvist, M., and Irwin, R.: Achieving the SDGs through interdisciplinary research in global health, Scand J Public Health., 47, 793-795, https://doi.org/10.1177/1403494818812637, 2019.

Hirabayashi, Y., Mahendran, R., Koirala, S., Konoshima, L., Yamazaki, D., Watanabe, S., Kim, H., and Kanae, S.: Global flood risk under climate change, Nat Clim Change., 3, 816-821, https://doi.org/10.1038/nclimate1911, 2013.

Iglesias, V., Braswell, A. E., Rossi, M. W., Joseph, M. B., McShane, C., Cattau, M., Koontz, M. J., McGlinchy, J., Nagy, R. C., Balch, J., Leyk, S., and Travis, W. R.: Risky Development: Increasing Exposure to Natural Hazards in the United States, Earth's Future., 9, e2020EF001795, https://doi.org/10.1029/2020EF001795, 2021.

Izumi, T., Shaw, R., Ishiwatari, M., Djalante, R., Komino, T., Sukhwani, V., and Adu Gyamfi, B.: 30 Innovations linking disaster risk reduction with sustainable development goals, Keio University, Tokyo, Japan, 2020.

582 Johansen, P. H., Ejrnæs, R., Kronvang, B., Olsen, J. V., Præstholm, S., Schou, J. S., and Johansen, S. K.: Exploring the interdisciplinary potential of the Agenda2030 - Interactions between five Danish societal demands for sustainable land use, Land Use Policy., 94, 104501, https://doi.org/10.1016/j.landusepol.2020.104501, 2020.

Johnston, B. and van de Lindt, J. W.: Barriers and Possibilities for Interdisciplinary Disaster Science Research: Critical Appraisal of the Literature, Nat Hazards Rev., 23, 04021053, https://doi.org/10.1061/(ASCE)NH.1527-6996.0000520, 2022. JRC (Joint Research Centre): Science for disaster risk management 2017: knowing better and losing less, European 
King, N.: Using templates in the thematic analysis of text. In: Cassell, C., Symon, G. (Eds.), Essential guide to qualitative methods in organisational research, 257-270. London, UK: Sage., 2004.

Kreibich, H., de Ruiter, M.C., Goda, K., Keiler, M., Suppasri, A. and Malamud, B.D.: Critical research in the water-related multi-hazard field, Nat. Sustain., https://doi.org/10.1038/s41893-021-00833-0, 2021.

Leal Filho, W., Lovren, V. O., Will, M., Salvia, A. L., and Frankenberger, F.: Poverty: A central barrier to the implementation

594 of the UN Sustainable Development Goals, Environ Sci Policy., 125, 96-104, https://doi.org/10.1016/j.envsci.2021.08.020, 2021.

Lerner-Lam, A.: Assessing global exposure to natural hazards: Progress and future trends, Environ Hazards-UK., 7, 10-19, https://doi.org/10.1016/j.envhaz.2007.04.007, 2007.

Luebken, U. and Mauch, C.: Uncertain Environments: Natural Hazards, Risk and Insurance in Historical Perspective, Environ Hist-UK., 17, 1-12, https://doi.org/10.3197/096734011X12922358301012, 2011.

600 Mazzoleni, M., Mård, J., Rusca, M., Odongo, V., Lindersson, S., and Di Baldassarre, G.: Floodplains in the Anthropocene: A Global Analysis of the Interplay Between Human Population, Built Environment, and Flood Severity, Water Resour Res., 57, e2020WR027744, https://doi.org/10.1029/2020WR027744, 2021.

Miles, M. and Huberman, M.: An expanded sourcebook: qualitative data analysis, 2nd ed., SAGE Publications, London, UK, 1994.

Nowell, L. S., Norris, J. M., White, D. E., and Moules, N. J.: Thematic Analysis: Striving to Meet the Trustworthiness Criteria, 606 Int J Qual Meth., 16, 1609406917733847, https://doi.org/10.1177/1609406917733847, 2017.

NVivo: Qualitatitive Data Analysis Version 1.5 [Online] Available at: https://www.qsinternational.com/nvivo-qualitativedata-analysis-software/home, 2021 [Accessed 1 October 2021].

O'Keefe, P., Westgate, K., and Wisner, B.: Taking the naturalness out of natural disasters, Nature., 260, 566-567, https://doi.org/10.1038/260566a0, 1976.

OECD (Organisation for Economic Co-operation and Development): Revised field of science and technology (FOS) 612 classification in the Frascati manual. Directorate for Science, Technology and Industry, Committee for Scientific and Technological Policy. Working Party of National Experts on Science and Technology Indicators., Organisation for Economic Co-operation and Development, Paris, France, 2007.

OECD (Organisation for Economic Co-operation and Development): Global modelling of natural hazard risks: enhancing existing capabilities to address new challenges, Organization for Economic Co-operation and Development, Paris, France, 2012.

618 Paul, J. D., Buytaert, W., Allen, S., Ballesteros-Cánovas, J. A., Bhusal, J., Cieslik, K., Clark, J., Dugar, S., Hannah, D. M., Stoffel, M., Dewulf, A., Dhital, M. R., Liu, W., Nayaval, J. L., Neupane, B., Schiller, A., Smith, P. J., and Supper, R.: Citizen science for hydrological risk reduction and resilience building, Wiley Interdisciplinary Reviews: Water., 5, e1262, https://doi.org/10.1002/wat2.1262, 2018.

Paulus, T. M. and Lester, J. N.: Using software to support qualitative data analysis, 2020. 
Peek, L. A. and Mileti, D. S.: The history and future of disaster research, in: Handbook of environmental psychology, John

Peek, L. and Guikema, S.: Interdisciplinary Theory, Methods, and Approaches for Hazards and Disaster Research: An Introduction to the Special Issue, Nat Hazards Rev., 41, 1047-1058, https://doi.org/10.1111/risa.13777, 2021.

Poursanidis, D. and Chrysoulakis, N.: Remote Sensing, natural hazards and the contribution of ESA Sentinels missions, Remote Sensing Applications: Society and Environment., 6, 25-38, https://doi.org/10.1016/j.rsase.2017.02.001, 2017.

Robins, C. S. and Eisen, K.: Strategies for the Effective Use of NVivo in a Large-Scale Study: Qualitative Analysis and the Repeal of Don’t Ask, Don’t Tell, Qual Inq., 23, 768-778, https://doi.org/10.1177/1077800417731089, 2017.

Shi, P., Ye, T., Wang, Y., Zhou, T., Xu, W., Du, J., Wang, J., Li, N., Huang, C., Liu, L., Chen, B., Su, Y., Fang, W., Wang, M., Hu, X., Wu, J., He, C., Zhang, Q., Ye, Q., Jaeger, C., and Okada, N.: Disaster Risk Science: A Geographical Perspective and a Research Framework, Int J Disaster Risk Sci., 11, 426-440, https://doi.org/10.1007/s13753-020-00296-5, 2020.

Sidle, R. C., Taylor, D., Lu, X. X., Adger, W. N., Lowe, D. J., de Lange, W. P., Newnham, R. M., and Dodson, J. R.: Interactions of natural hazards and society in Austral-Asia: evidence in past and recent records, Quatern Int., 118-119, 181203, https://doi.org/10.1016/S1040-6182(03)00137-X, 2004.

Smith, M. and Bricker, S.: Sustainable Cities and Communities. In Geosciences and the Sustainable Development Goals (pp. 259-282). Springer, Cham, 2021.

Strauch, R., Istanbulluoglu, E., and Riedel, J.: A new approach to mapping landslide hazards: a probabilistic integration of empirical and physically based models in the North Cascades of Washington, USA, Nat. Hazards Earth Syst. Sci., 19, 24772495, https://doi.org/10.5194/nhess-19-2477-2019, 2019.

642 Ujjwal, K. C., Garg, S., Hilton, J., Aryal, J., and Forbes-Smith, N.: Cloud Computing in natural hazard modeling systems: Current research trends and future directions, Int J Disast Risk R., 38, 101188, https://doi.org/10.1016/j.ijdrr.2019.101188, 2019.

UNDRR (United Nations Office for Disaster Risk Reduction): Disaster risk reduction and resilience in the 2030 Agenda for sustainable development, United Nations Office for Disaster Risk Reduction, Geneva, Switzerland, 2015.

UNISDR (United Nations International Strategy for Office for Disaster Risk): Sendai Framework for Disaster Risk Reduction 648 2015-2030, United Nations Office for Disaster Risk Reduction, Geneva, Switzerland, 2015.

United Nations: Standard country or area codes for statistical use (M49), Geography Regions. [Online] Available at: https://unstats.un.org/unsd/methodology/m49/, 2021 [Accessed 15 November 2021].

Ward, P. J., Daniell, J., Duncan, M., Dunne, A., Hananel, C., Hochrainer-Stigler, S., Tijssen, A., Torresan, S., Ciurean, R., Gill, J., Sillmann, J., Couasnon, A., Koks, E., Padrón-Fumero, N., Tatman, S., Tronstad Lund, M., Adesiyun, A., Aerts, J., Alabaster, A., Butler, B., Campillo Torres, C., Critto, A., Hernández Martin, R., Machado, M., Mysiak, J., Orth, R., Palomino, research agenda towards Disaster Risk Management pathways in multi-risk assessment, Nat. Hazards Earth Syst. Sci., 1-15, https://doi.org/10.5194/nhess-2021-326, 2021. 
https://doi.org/10.5194/nhess-2022-55

Preprint. Discussion started: 23 February 2022

(C) Author(s) 2022. CC BY 4.0 License.

(c) (1)

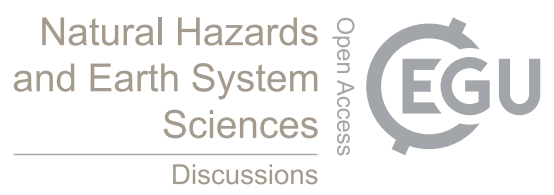

Wartman, J., Berman, J. W., Bostrom, A., Miles, S., Olsen, M., Gurley, K., Irish, J., Lowes, L., Tanner, T., Dafni, J., Grilliot, M., Lyda, A., and Peltier, J.: Research needs, challenges, and strategic approaches for natural hazards and disaster reconnaissance, Front. Built Environ., 6, article 573068, https://doi.org/10.3389/fbuil.2020.573068, 2020.

660 WMO: WMO Atlas of Mortality and Economic Losses from Weather, Climate and Water Extremes (1970-2019) (WMO-No. 1267), WMO, Geneva, 90 p. pp., 2021. 